\title{
Erratum to: Predicting hydration free energies using all-atom molecular dynamics simulations and multiple starting conformations
}

Pavel V. Klimovich • David L. Mobley

Published online: 23 January 2013

(C) Springer Science+Business Media Dordrecht 2013

Erratum to: J Comput Aided Mol Des (2010)

24:307-316

DOI 10.1007/s10822-010-9343-7

The original article is correct as printed. However, the supporting supplementary information was not deposited with the original article, and is provided here.

The online version of the original article can be found under doi:10.1007/s10822-010-9343-7.

Electronic supplementary material The online version of this article (doi:10.1007/s10822-012-9622-6) contains supplementary material, which is available to authorized users.

P. V. Klimovich · D. L. Mobley ( $)$

Department of Chemistry, University of New Orleans, 2000 Lakeshore Drive, 70148 New Orleans, LA, USA

e-mail: dmobley@gmail.com 